\title{
SPK: ALGORITMA MULTI-ATTRIBUTE UTILITY THEORY (MAUT) PADADESTINASI TUJUAN WISATA LOKAL DI KOTA SIDAMANIK
}

\author{
Edy Satria ${ }^{1}$, Nurul Atina ${ }^{2}$, Maria Etty Simbolon ${ }^{3}$, Agus Perdana Windarto ${ }^{4}$ \\ 1,2,3,4 Sekolah Tinggi Ilmu Komputer Tunas Bangsa (STIKOM Tunas Bangsa) \\ Jl. Jendral Sudirman Blok A No.1/2/3 Pematangsiantar, Medan, Indonesia, 21127 \\ 1edysatria959@gmail.com, ${ }^{4}$ agus.perdana@amiktunasbangsa.ac.id
}

\begin{abstract}
Abstrak-Wisata lokal saat ini berpotensi untuk dikembangkan sebagai salah satu sumber pendapatan daerah dengan mendayagunakan sumber daya yang dapat memberikan sumbangan bagi pembangunan ekonomi pada suatu daerah tersebut. Kota Sidamanik merupakan kota yang mempunyai banyak wisata alam yang masih alami. Dan juga suasana alam yang indah dikelilingi perkebunan teh yang sangat menarik perhatian para wisatawan lokal maupun asing. Dalam hal ini terkadang banyak para wisatawan bingung untuk menentukan wisata mana yang akan mereka kunjungi untuk dapat menyesuaikan keinginan mereka, mengingat beberapa wisata yang ada di kota Sidamanik. Penelitian ini menggunakan Metode MAUT (Multi-Attribute Utility Theory) untuk merekomendasikan destinasi wisata lokal yang ada di kota Sidamanik. Pengolahan nilai menggunakan metode Maut akan menghasilkan nilai rangking. Hasil dari penelitian ini yaitu rekomendasidestinasi tujuan wisata lokal di Kota Sidamanik adalah wisata Bah Biak. Hasil nilai yang di peroleh dari wisata lokal Bah Biak adalah 0,847 dan menempati nilai tertinggi dari keempat wisata lokal yang ada di Kota Sidamanik Kab. Simalungun Provinsi Sumatra Utara.
\end{abstract}

Keywords— Wisata Lokal, MAUT, Sistem Pendukung Keputusan, Sidamanik.

\section{PENDAHULUAN}

Mengapa destinasi tujuan wisata? Pariwisata di Indonesia merupakan sektor Ekonomi penting di Indonesia. Pada tahun 2000 pariwisata menempati urutan ketiga dalam hal penerimaan devisa setelah komoditi minyak dan gas bumi serta minyak kelapa sawit. Berdasarkan data tahun 2016, jumlah wisatawan mancanegara yang datang ke Indonesia sebesar 11.525.963 juta lebih atau tumbuh sebesar 10,79 \% dibandingkan tahun sebelumnya.

Seiring perkembangan zaman, destinasi wisata di Indonesia mulai bertambah dan berkembang terkhusus wisata lokal di Kabupaten Simalungun tepatnya di Kota Sidamanik Provinsi Sumatra Utara. Hal ini dikarenakan wisata lokal merupakan sektor yang dianggap menguntungkan dan sangat berpotensi untuk meningkatkan pendapatan usaha masyarakat pada kota tersebut. Ada beberapa destinasi wisata lokal yang ada di kota Sidamanik yaitu: 1. AEK MANIK, 2. AEK SIMATAHUTING, 3. BAH BIAK, 4. BAH DAMANIK. Dari keempat wisata tersebut, terkadang banyak pengunjung dari luar kota ataupun turis lokal bingung untuk menentukan lokasi wisata sesuai keinginan mereka. Dari segi keindahan alam, keamanan lahan parkir, biaya, jarak, waktu, serta sarana dan prasarana itu yang menjadikan alasan untuk mereka berwisata di Kota Sidamanik. Maka dari itu, rekomendasi tempat wisata lokal di Kota Sidamanik sangat penting untuk menciptakan kepuasan para wisatawan. Banyak cabang ilmu komputer yang dapat menyelesaikan permasalahan yang bersifat kompleks. Hal ini terbukti dari penelitian terdahulu oleh para peneliti dalam menyelesaikan permasalahan[1][2] dalam bidang data Mining, [3][4] dalam bidang jaringan saraf tiruan, [5][6] dalam bidang sistem pendukung keputusan. Berdasarkan penjelasan tersebut, peneliti menggunakan sistem pendukung keputusanuntuk dapat menyelesaikan masalah diatas. Dalam hal ini peneliti mengambil salah satu metode yaitu metode Metode MultiAttribute Utility Theory (MAUT).

Metode Multi-Attribute Utility Theory (MAUT) adalah "suatu metode perbandingan kuantitatif yang biasanya mengkombinasikan pengukuran atas biaya resiko dan keuntungan yang berbeda. Setiap kriteria yang ada memiliki beberapa alternatif yang mampu memberikan solusi. Untuk mencari alternatif yang mendekati dengan keinginan user maka untuk mengidentifikasikan nya dilakukan perkalian terhadap skala prioritas yang sudah ditentukan. Sehingga hasil yang terbaik dan paling mendekati dari alternatifalternatif tersebut yang akan diambil sebagai solusi[7].Diharapkan penelitian ini dapat memberikan kontribusi masukan kepada pemerintah setempat untuk membenahi diri agar mendapatkan pendapatan daerah di Kota Sidamanik.

\section{TINJAUAN PUSTAKA}

\section{A. Sistem Pendukung Keputusan (SPK)}

Sistem pendukung keputusan merupakan sistem informasi interaktif yang menyediakan informasi, pemodelan, dan pemanipulasian data yang digunakan untuk membantu pengambilan keputusan pada situasi yang semi- terstruktur dan tidak terstruktur di mana 
Page|169 suatu permasalahan. Adapun tools yang digunakan

tak seorang pun tahu secara pasti bagaimana keputusan seharusnya dibuat[8]. DSS disusun oleh beberapa komponen yaitu basis data, basis model dan user interface[9]. Prototipe DSS ini menggunakan software sebagai pedekatan untuk menyelesaikan adalah Expert Choice[10].

\section{B. Definisi Metode MAUT}

Multi Atribute Utility Theory (MAUT) merupakan suatu skema yang evaluasi akhir, $\mathrm{v}(\mathrm{x})$ dari suatu objek $\mathrm{x}$ didefinisikan sebagai bobot yang dijumlahkan dengan suatu nilai yang relevan terhadap nilai dimensinya. Ungkapan yang biasa digunakan untuk menyebutnya adalah nilai utilitas. MAUT digunakan untuk merubah dari beberapa kepentingan kedalam nilai numerik dengan skala 0-1 dengan 0 mewakili pilihan terburuk dan 1 terbaik. Hal ini memungkinkan perbandingan langsung yang beragam ukuran. Hasil akhirnya adalah urutan peringkat dari evaluasi yang menggambarkan pilihan dari para pembuat keputusan. Nilai evaluasi seluruhnya dapat didefinisikan dengan persamaan:

$$
V(x) \sum_{i=1}^{n} W j . X i j \ldots \ldots \ldots \ldots(1)
$$

Dimana $\mathrm{V}(\mathrm{x})$ merupakan nilai evaluasi dari sebuah objek ke i dan wi merupakan bobot yang menentukan nilai dari seberapa penting elemen ke i terhadap elemen lainnya. Sedangkan $n$ merupakan jumlah elemen. Total dari bobot adalah 1. Secara ringkas langkah-langkah dalam metode MAUT adalah sebagai berikut [2]:

1. Pecah sebuah keputusan ke dalam dimensi yang berbeda.

2. Tentukan bobot alternatif pada masing” dimensi.

3. Daftar semua alternatif

4. Masukkan utility untuk masing-masing alternatif sesuai atributnya.

5. Kalikan utility dengan bobot untuk menentukan nilai masing-masing alternatif.

Normalisasi matriks:

$$
U_{(X)}=\frac{x-x i^{-}}{x i^{+}+x i^{-}} \ldots \ldots \ldots \ldots \ldots
$$

Keterangan:

$$
\begin{aligned}
\mathrm{U}(\mathrm{x}) & =\text { Normalisasi bobot alternatif } \mathrm{x} \\
\mathrm{x} & =\text { Bobot alternatif } \\
x i^{-} & =\text {Bobot terburuk (minimum) dari kriteria ke- } \\
\mathrm{x} &
\end{aligned}
$$

$x i^{+}=$Bobot terbaik (maximum) dari kriteria ke-x

[7].

\section{Destinasi Wisata}

Sektor pariwisata saat ini berpotensial untuk dikembangkan sebagai salah satu sumber pendapatan daerah. Sektor ini sangat menarik wisatawan baik local ataupun internasional. Dengan adanya tempat wisata atau objek wisata mampu membantu meredakan kepenatan dalam pikiran dari beberapa aktivitas. Banyak wisatawan bingung untuk menentukan objek wisata yang akan dikunjungi diantaranya penentuan lokasi, fasilitas, waktu, biaya, jarak, transportasi dan keamanan tempat wisata. Industri pariwisata telah tumbuh dan berkembang serta merupakan salah satu sumber pemasukan devisa sebuah negara. Hal ini menandakan kegiatan melakukan pariwisata sudah menjadi kebutuhan dasar setiap manusia sebagaimana kebutuhan lainnya. Kesibukan yang padat dengan aktivitas yang sangat beragam membuat manusia berusaha untuk mencari cara agar dapat melepaskan dari semua tekanan yang dialami saat menyelesaikan pekerjaannya[11]

\section{METODE PENELITIAN}

\section{A. Prosedur Penelitian}

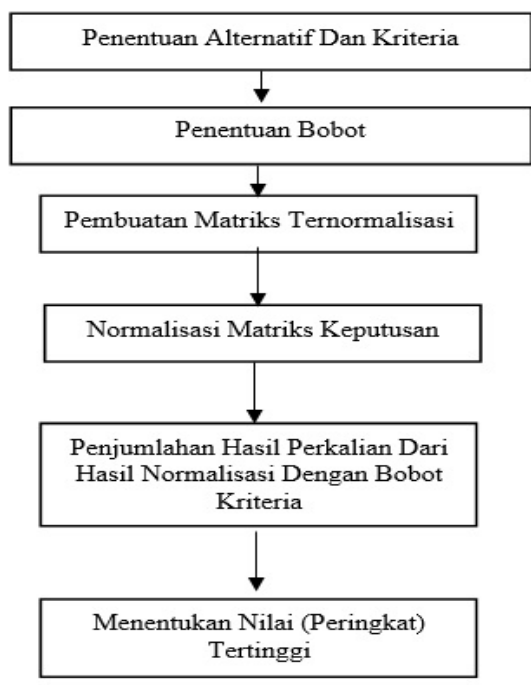

Gbr 1. Prosedur penelitian Multi Atribute Utility Theory (MAUT)

Prosedur penelitian yang dilakukan adalah sebagai berikut :

1. Penentuan alternatif dan kriteria

Pada tahap ini menentukan alternatif yang ada pada studi kasus Wisata lokal yang ada di Kota Sidamanik dan menentukan kriteria pada destinasi wisata lokal yang ada.

2. Penentuan bobot

Pada tahapan ini adalah proses pembagian kuesioner kepada wisatawan untuk menentukan bobot 
pada setiap kriteria yang akan digunakan untuk proses Metode MAUT.

3. Pembuatan Matriks Ternormalisasi

Pada tahapan ini di lakukan pembuatan matriks normalisasi yang akan dikelompokkan berdasarkan

Page | 170 kriteria dari data kuesioner.

4. Normalisasi matriks keputusan

Pada tahap ini dilakukan perhitungan normalisasi matriks keputusan yaitu dengan pembagian bobot alternatif, bobot terburuk (minimum) dari kriteria ke$\mathrm{x}$ dan bobot terbaik (maksimum) dari kriteria ke- $\mathrm{x}$.

5. Penjumlahan hasil perkalian dari hasil normalisasi dengan bobot kriteria

Pada tahap ini dilakukan penjumlahan hasil perkalian dari hasil normalisasi bobot kriteria. Yaitu elemen baris kriteria ternormalisasi dengan bobot yang sudah ditentukan.

6. Menentukan nilai (Peringkat) Tertinggi

Pada tahap ini di dapatkan hasil perkalian matriks ternormalisasi yang akan menentukan nilai (peringkat) tertinggi dari studi kasus penelitian.

\section{HASIL DAN PEMBAHASAN}

\section{A. Analisa Metode MAUT}

Berikut tahapan dalam mengimplementasikan metode MAUT untuk merekomendasikan wisata lokal di Kota Sidamanik, yaitu sbb:

\section{Menentukan Alternatif}

Terdapat 4 alternatif pada studi kasus destinasi wisata lokal yang ada di kota Sidamanik, diantaranya sbb :

TABEL I

ALTERNATIF

\begin{tabular}{|c|l|}
\hline No & Alternatif \\
\hline 1 & Aek Manik (A1) \\
\hline 2 & Bah Damanik (A2) \\
\hline 3 & Bah Biak (A3) \\
\hline 4 & Aek Simatahuting (A4) \\
\hline
\end{tabular}

2. Menentukan kriteria dan bobot pada setiap alternatif

Proses menentukan kriteria dan bobot pada setiap alternatif sangatlah dibutuhkan. Adapun kriteria pada alternatif diatas adalah sebagai berikut:

TABEL II

KRITERIA DAN BOBOT

\begin{tabular}{|l|l|c|}
\hline No & \multicolumn{1}{|c|}{ Kriteria } & $\begin{array}{c}\text { Bobot } \\
\text { Kriteria }\end{array}$ \\
\hline 1 & Keindahan Alam (C1) & $0,25-0,9$ \\
\hline 2 & Keamanan (C2) & $0,25-0,9$ \\
\hline 3 & Biaya (C3) & $0,25-0,9$ \\
\hline 4 & Jarak (C4) & $0,25-0,9$ \\
\hline 5 & Waktu (C5) & $0,25-0,9$ \\
\hline 6 & Sarana dan Prasarana (C6) & $0,25-0,9$ \\
\hline
\end{tabular}

Setiap persepsi penilaian diberi penilaian SS(Sangat Setuju $)=0.9, \mathrm{~S}($ Setuju $)=0.75, \mathrm{R}($ Ragu-ragu $)=0.5$, TS $($ Tidak Setuju $)=0.25$. Berikut data penilaian terhadap wisatawan yang telah diteliti dan di konversikan ke dalam MS. EXCEL :

TABEL III

WISATA AEK MANIK

\begin{tabular}{|l|l|l|l|l|l|l|}
\hline $\begin{array}{c}\text { Responden } \\
\text { (R) }\end{array}$ & C1 & C2 & C3 & C4 & C5 & C6 \\
\hline R1 & 0,86 & 0,67 & 0,77 & 0,67 & 0,63 & 0,73 \\
\hline R2 & 0,79 & 0,75 & 0,75 & 0,75 & 0,83 & 0,69 \\
\hline R3 & 0,75 & 0,67 & 0,67 & 0,80 & 0,83 & 0,71 \\
\hline R4 & 0,83 & 0,67 & 0,77 & 0,68 & 0,83 & 0,88 \\
\hline R5 & 0,79 & 0,75 & 0,75 & 0,55 & 0,75 & 0,75 \\
\hline R6 & 0,75 & 0,67 & 0,75 & 0,80 & 0,50 & 0,73 \\
\hline R7 & 0,75 & 0,58 & 0,75 & 0,80 & 0,50 & 0,75 \\
\hline R8 & 0,80 & 0,90 & 0,90 & 0,68 & 0,58 & 0,90 \\
\hline R9 & 0,63 & 0,80 & 0,85 & 0,90 & 0,58 & 0,85 \\
\hline R10 & 0,75 & 0,72 & 0,50 & 0,67 & 0,63 & 0,58 \\
\hline Rata Rata & 0,77 & 0,72 & 0,75 & 0,73 & 0,66 & 0,76 \\
\hline
\end{tabular}

TABEL IV

WISATA BAH DAMANIK

\begin{tabular}{|l|l|l|l|l|l|l|}
\hline Responden (R) & C1 & C2 & C3 & C4 & C5 & C6 \\
\hline R1 & 0,56 & 0,50 & 0,75 & 0,50 & 0,75 & 0,54 \\
\hline R2 & 0,44 & 0,55 & 0,33 & 0,47 & 0,58 & 0,59 \\
\hline R3 & 0,63 & 0,58 & 0,42 & 0,50 & 0,63 & 0,58 \\
\hline R4 & 0,75 & 0,75 & 0,50 & 0,75 & 0,50 & 0,63 \\
\hline R5 & 0,76 & 0,33 & 0,85 & 0,58 & 0,75 & 0,66 \\
\hline R6 & 0,73 & 0,80 & 0,80 & 0,67 & 0,75 & 0,85 \\
\hline R7 & 0,75 & 0,67 & 0,75 & 0,67 & 0,75 & 0,83 \\
\hline R8 & 0,50 & 0,33 & 0,85 & 0,80 & 0,83 & 0,42 \\
\hline R9 & 0,63 & 0,63 & 0,75 & 0,75 & 0,75 & 0,71 \\
\hline R10 & 0,31 & 0,42 & 0,75 & 0,33 & 0,83 & 0,44 \\
\hline Rata Rata & 0,61 & 0,56 & 0,68 & 0,60 & 0,62 & 0,62 \\
\hline
\end{tabular}

TABEL V

WISATA BAH BIAK

\begin{tabular}{|c|c|c|c|c|c|c|}
\hline $\begin{array}{c}\text { Responden } \\
\text { (R) }\end{array}$ & C1 & C2 & C3 & C4 & C5 & C6 \\
\hline R1 & 0,75 & 0,58 & 0,85 & 0,63 & 0,90 & 0,80 \\
\hline R2 & 0,75 & 0,67 & 0,80 & 0,42 & 0,75 & 0,75 \\
\hline R3 & 0,79 & 0,63 & 0,72 & 0,50 & 0,75 & 0,75 \\
\hline R4 & 0,75 & 0,72 & 0,90 & 0,72 & 0,90 & 0,73 \\
\hline R5 & 0,75 & 0,67 & 0,75 & 0,67 & 0,75 & 0,75 \\
\hline R6 & 0,79 & 0,67 & 0,75 & 0,42 & 0,75 & 0,75 \\
\hline R7 & 0,79 & 0,80 & 0,90 & 0,85 & 0,83 & 0,85 \\
\hline R8 & 0,75 & 0,50 & 0,75 & 0,72 & 0,70 & 0,71 \\
\hline R9 & 0,73 & 0,50 & 0,85 & 0,85 & 0,90 & 0,78 \\
\hline R10 & 0,79 & 0,72 & 0,85 & 0,72 & 0,75 & 0,85 \\
\hline Rata Rata & 0,76 & 0,65 & 0,81 & 0,65 & 0,80 & 0,77 \\
\hline
\end{tabular}

TABEL VI

WISATA AEK SIMATAHUTING

\begin{tabular}{|l|l|l|l|l|l|l|}
\hline Responden (R) & C1 & C2 & C3 & C4 & C5 & C6 \\
\hline R1 & 0,63 & 0,50 & 0,77 & 0,58 & 0,83 & 0,54 \\
\hline R2 & 0,75 & 0,67 & 0,75 & 0,75 & 0,63 & 0,75 \\
\hline R3 & 0,79 & 0,58 & 0,75 & 0,33 & 0,75 & 0,67 \\
\hline R4 & 0,76 & 0,42 & 0,67 & 0,63 & 0,90 & 0,63 \\
\hline R5 & 0,79 & 0,58 & 0,50 & 0,67 & 0,63 & 0,67 \\
\hline R6 & 0,79 & 0,50 & 0,75 & 0,42 & 0,75 & 0,73 \\
\hline R7 & 0,79 & 0,50 & 0,80 & 0,58 & 0,50 & 0,69 \\
\hline
\end{tabular}




\begin{tabular}{|l|l|l|l|l|l|l|}
\hline R8 & 0,79 & 0,72 & 0,85 & 0,72 & 0,63 & 0,67 \\
\hline R9 & 0,79 & 0,50 & 0,85 & 0,75 & 0,63 & 0,57 \\
\hline R10 & 0,83 & 0,75 & 0,75 & 0,80 & 0,75 & 0,83 \\
\hline Rata Rata & 0,77 & 0,57 & 0,74 & 0,62 & 0,70 & 0,67 \\
\hline
\end{tabular}

Page|171 Setelah melakukan rating sub-kriteria pada setiap kriteria, tahap selanjutnya adalah memberikan bobot preferensi dari setiap kriteria wisata lokal. Adapun bobot preferensi nya yaitu:
a) Keindahan alam $=0.35$
b) Keamanan $=0.15$
c) Biaya $=0.1$
d) Jarak $=0.1$
e) Waktu $=0.1$
f) Sarana dan Prasarana $=0.2$

Berikut ini contoh perhitungan Metode MAUT :

TABEL VII

NORMALISASI MATRIKS DAN BOBOT PREFERENSI

\begin{tabular}{|c|l|c|c|c|r|r|r|}
\hline No & Wisata (A) & C1 & C2 & C3 & C4 & C5 & C6 \\
\hline 1 & A1 & 0,77 & 0,72 & 0,75 & 0,73 & 0,66 & 0,76 \\
\hline 2 & A2 & 0,61 & 0,56 & 0,68 & 0,6 & 0,71 & 0,62 \\
\hline 3 & A3 & 0,76 & 0,65 & 0,81 & 0,65 & 0,8 & 0,77 \\
\hline 4 & A4 & 0,77 & 0,57 & 0,74 & 0,62 & 0,7 & 0,67 \\
\hline \multicolumn{2}{|l|}{ Bobot Preferensi } & 0,35 & 0,15 & 0,1 & 0,1 & 0,1 & 0,2 \\
\hline
\end{tabular}

Normalisasi Matriks Destinasi wisata ditentukan dengan Rumus :

$$
U_{(X)}=\frac{x-x i^{-}}{x i^{+}+x i^{-}} \ldots \ldots \ldots \ldots \ldots
$$

Keterangan:

$\mathrm{U}(\mathrm{x})=$ Normalisasi bobot alternatif $\mathrm{x}$

$\mathrm{x}=$ Bobot alternatif

$x i^{-}=$Bobot terburuk (minimum) dari kriteria ke$\mathrm{x}$

$x i^{+}=$Bobot terbaik (maximum) dari kriteria ke-x

Berikut contoh perhitungan matriks normalisasi destinasi wisata :

1. Nama Alternatif : Aek Manik (A1)

$$
\begin{aligned}
& \mathrm{A} 1_{1}=\frac{0,77-0,61}{0,77-0,61}=1 \quad \mathrm{~A} 1_{2}=\frac{0,72-0,56}{0,72-0,56}=1 \\
& \mathrm{~A} 1_{3}=\frac{0,75-0,68}{0,81-0,68}=0,53 \quad \mathrm{~A} 1_{4}=\frac{0,73-0,60}{0,73-0,60}=
\end{aligned}
$$$$
1
$$

$\mathrm{A} 1_{5}=\frac{0,66-0,66}{0,80-0,66}=0$

$\mathrm{A} 1_{6}=\frac{0,76-0,62}{0,77-0,62}=$

0,93
2. Nama alternatif : Bah Damanik (A2)

$$
\mathrm{A} 2_{1}=\frac{0,61-0,61}{0,77-0,61}=0 \quad \mathrm{~A} 2_{2}=\frac{0,56-0,56}{0,72-0,56}=
$$

0

$$
\mathrm{A} 2_{3}=\frac{0,68-0,68}{0,81-0,68}=0 \quad \mathrm{~A} 2_{4}=\frac{0,60-0,60}{0,73-0,60}=
$$

0

$$
\mathrm{A} 2_{5}=\frac{0,71-0,66}{0,80-0,6}=0,35 \quad \mathrm{~A} 2_{6}=\frac{0,62-0,62}{0,77-0,62}=
$$

0

3. Nama Alternatif : Bah Biak (A3)

$$
\begin{aligned}
& \mathrm{A}_{1}=\frac{0,76-0,61}{0,77-0,61}=0,93 \quad \mathrm{~A}_{2}=\frac{0,65-0,56}{0,72-0,56}= \\
& 0,56
\end{aligned}
$$

$$
\mathrm{A}_{3}=\frac{0,81-0,68}{0,81-0,68}=1 \quad \mathrm{~A}_{4}=\frac{0,65-0,60}{0,73-0,60}=
$$$$
0,38
$$

$$
\mathrm{A}_{5}=\frac{0,80-0,66}{0,81-0,66}=1 \quad \mathrm{~A}_{6}=\frac{0,77-0,62}{0,77-0,62}=
$$

1

4. Nama Alternatif : Aek Simatahuting (A4)

$$
\begin{aligned}
& \mathrm{A} 4_{1}=\frac{0,77-0,61}{0,77-0,61}=1 \quad \mathrm{~A}_{2}=\frac{0,57-0,56}{0,72-0,56}= \\
& 0,06
\end{aligned}
$$$$
\mathrm{A} 4_{3}=\frac{0,74-0,68}{0,81-0,68}=0,46 \quad \mathrm{~A} 4_{4}=\frac{0,62-0,60}{0,73-0,60}=
$$$$
0,15
$$$$
\mathrm{A} 4_{5}=\frac{0,70-0,66}{0,80-0,66}=0,28 \quad \mathrm{~A} 4_{6}=\frac{0,67-0,62}{0,77-0,62}=
$$$$
0,33
$$

TABEL VIII

HASIL NORMALISASI MATRIKS

\begin{tabular}{|c|l|c|c|c|c|c|c|}
\hline No & Wisata $(\mathrm{A})$ & $\mathrm{C} 1$ & $\mathrm{C} 2$ & $\mathrm{C} 3$ & $\mathrm{C} 4$ & $\mathrm{C} 5$ & $\mathrm{C} 6$ \\
\hline 1 & A1 & 1 & 1 & 0,53 & 1 & 0 & 0,93 \\
\hline 2 & A2 & 0 & 0 & 0 & 0 & 0,35 & 0 \\
\hline 3 & A3 & 0,93 & 0,56 & 1 & 0,38 & 1 & 1 \\
\hline 4 & A4 & 1 & 0,06 & 0,46 & 0,15 & 0,28 & 0,33 \\
\hline
\end{tabular}

Tahap selanjutnya akan dilakukan perkalian matrik normalisasi dengan bobot preferensi denganmenggunakanrumus:

$$
V(x) \sum_{i=1}^{n} W j . X i j
$$

Berikut perhitungan perkalian matrik normalisasi dengan menggunakan persamaan (1): 


$$
\begin{aligned}
\text { A1 }= & (0,35 * 1)+(0,15 * 1)+(0,1 * 0,53)+(0,1 * 1) \\
& +(0,1 * 0)+(0,2 * 0,93)=0,839 \\
\text { A2 }= & (0,35 * 0)+(0,15 * 0)+(0,1 * 0)+(0,1 * 0)+ \\
& (0,1 * 35)+(0,2 * 0)=0,035 \\
\text { A3 }= & (0,35 * 0,93)+(0,15 * 0,56)+(0,1 * 1)+(0,1 \\
& * 0,38)+(0,1 * 1)+(0,2 * 1)=0,847 \\
\text { A4 }= & (0,35 * 1)+(0,15 * 0,06)+(0,1 * 0,46)+(0,1 \\
& * 0,15)+(0,1 * 0,28)+(0,2 * 0,33)=0,514
\end{aligned}
$$

Dari hasil persamaan (1) maka akan dihasilkan perkalian matrik normalisasi yang ditampilkan pada tabel V.

TABEL IX

HASIL PERKALIAN MATRIK TERNORMALISASI DENGAN BOBOT PREFERENSI

\begin{tabular}{|c|l|l|c|}
\hline No & Wisata & Hasil & Rank \\
\hline 1 & Aek Manik & 0,839 & 2 \\
\hline 2 & Bah Damanik & 0,035 & 4 \\
\hline 3 & Bah Biak & 0,847 & 1 \\
\hline 4 & Aek Simatahuting & 0,514 & 3 \\
\hline
\end{tabular}

Hasil dari analisis dengan metode MAUT pada kasus rekomendasi tempat wisata untuk wisatawan di Kota Sidamanik dapat menghasilkan pilihan yang lebih objektif dengan penilaian Bah Biak $(0,847)$ sebagai penilaian tertinggi, disusul oleh Aek Manik $(0,839)$, Aek Simatahuting $(0,514)$ dan Bah Damanik $(0,035)$.

\section{KESIMPULAN}

Dari hasil perhitungan metode MAUT diatas dapat disimpulkan bahwa rekomendasi destinasi tujuan wisata lokal di Kota Sidamanik adalah wisata Bah Biak. Hasil nilai yang di peroleh dari wisata lokal Bah Biak adalah 0,847 dan menempati nilai tertinggi dari keempat wisata lokal yang ada di Kota Sidamanik Kab. Simalungun Provinsi Sumatra Utara.

\section{UCAPAN TERIMA KASIH}

Terima kasih kepada STIKOM (Sekolah Tinggi Ilmu Komputer) Tunas Bangsa yang telah memberikan dukungan kepada peneliti untuk dapat menyelesaikan penelitian ini. Dan juga terima kasih kepada bapak Agus Perdana Windarto yang telah membimbing penelitian ini hingga selesai.

\section{REFERENSI}

[1] A. P. Windarto, "Penerapan Data Mining Pada Ekspor BuahBuahan Menurut Negara Tujuan Menggunakan K-Means Clustering,” Techno.COM, vol. 16, no. 4, pp. 348-357, 2017.

[2] M. G. Sadewo, A. P. Windarto, and D. Hartama, "PENERAPAN DATAMINING PADA POPULASI DAGING AYAM RAS PEDAGING DI INDONESIA BERDASARKAN PROVINSI MENGGUNAKAN KMEANS CLUSTERING,” InfoTekJar (Jurnal Nas. Inform. dan Teknol. Jaringan), vol. 2, no. 1, pp. 60-67, 2017.

[3] Sumijan, A. P. Windarto, A. Muhammad, and Budiharjo, "Implementation of Neural Networks in Predicting the Understanding Level of Students Subject,” Int. J. Softw. Eng.
Its Appl., vol. 10, no. 10, pp. 189-204, 2016.

[4] M. Noor and H. Siregar, "Neural Network Analysis With Backpropogation In Predicting Human Development Index ( HDI ) Component by Regency / City In North Sumatera,” I nternational Journal O I In formation $S$ yste m T e c h n o logy, vol. 1, no. 1, pp. 22-33, 2017.

[5] A. Putrama and A. P. Windarto, "Analisis dalam menentukan produk bri syariah terbaik berdasarkan dana pihak ketiga menggunakan ahp,” CESS (Journal Comput. Eng. Syst. Sci., vol. 3, no. 1, pp. 60-64, 2018.

[6] P. P. P. A. N. W. F. I. R. H. Zer and A. P. Windarto, “Analisis Pemilihan Rekomendasi Produk Terbaik Prudential Berdasarkan Jenis Asuransi Jiwa Berjangka Untuk Kecelakaan Menggunakan Metode Analytic Hierarchy Process ( Ahp ),” CESS (Journal Comput. Eng. Syst. Sci., vol. 3, no. 1, pp. 78-82, 2018.

[7] M. Hidayat and P. A. Jusia, “Analisa dan Perancangan Sistem Pendukung Keputusan Untuk Penerimaan Karyawan PT . Dos Ni Roha Jambi Menggunakan Metode MAUT ( Multi Attribute Utility Theory ),” vol. 13, no. 1, 2018.

[8] Agus Perdana Windarto, "Implementasi metode topsis dan saw dalam memberikan reward pelanggan,” Kumpul. J. Ilmu Komput., vol. 4, no. 1, pp. 88-101, 2017.

[9] T. Imandasari and A. P. Windarto, "Sistem Pendukung Keputusan dalam Merekomendasikan Unit Terbaik di PDAM Tirta Lihou Menggunakan Metode Promethee,” J. Teknol. dan Sist. Komput., vol. 5, no. 4, p. 159, 2017.

[10] E. Lestari, "ANALISA SISTEM PENDUKUNG KEPUTUSAN UNTUK PROSES KENAIKAN JABATAN PADA PT . X,” vol. 1, no. 3, pp. 141-150, 2009.

[11] L. Marlinda, "SISTEM PENDUKUNG KEPUTUSAN PEMILIHAN TEMPAT WISATA YOGYAKARTA MENGGUNAKAN METODE ELimination Et Choix," Jurnal.Umj.Ac.Id/Index.Php/Semnastek, no. November, pp. 1-7, 2016. 